\title{
VARIATIONS IN THE BLOOD PRESSURE RESPONSE TO REPEATED ADMINISTRATION OF TETRAETHYL AMMONIUM CHLORIDE ${ }^{1}$
}

\author{
By JOSEPH E. LEVINSON, MORTON F. REISER AND EUGENE B. FERRIS, JR. \\ (From the Department of Internal Medicine, University of Cincinnati College of Medicine \\ and Cincinnati General Hospital, Cincinnati)
}

(Received for publication August 20, 1947)

It has been demonstrated by a number of investigators that temporary pharmacological denervation of the autonomic nervous system may be produced through the use of the tetraethyl ammonium ion by means of its action at the autonomic ganglia (1 to 5). In the course of experiments utilizing the tetraethyl ammonium ion in the study of neurogenic mechanisms in essential hypertension, variation in blood pressure response to this drug both in a given individual and in different individuals suggested the necessity of determining whether increasing tolerance may develop during the test period and whether the basic tone (due to humoral and other intrinsic factors) of the denervated arterial vascular tree is constant or varying. The results of numerous serial intravenous injections of tetraethyl ammonium chloride in 6 hypertensive patients are presented as a preliminary answer to these questions.

After entering the laboratory, these patients rested 30 minutes or more in the horizontal position before 5 baseline blood pressure readings were made at minute intervals. Four cubic centimeters (400 mgm.) of tetraethyl ammonium chloride ${ }^{2}$ were then injected into an arm vein and blood pressure readings made at 30 -second intervals for 5 minutes and thereafter at minute intervals for an additional 5 minutes. The mean of the pressure readings made before the injection was taken as the baseline, the lowest systolic-diastolic reading made after the injection was taken as the endpoint (tetraethyl ammonium chloride floor). This procedure was repeated serially with each patient at intervals of approximately 24 hours for 7 to 15 days.

Three hospital patients and 3 ambulatory patients were studied. Two of the patients were in-

1 The work described in this paper was aided in part by a grant from the Psychosomatic Research Fund of the National Committee for Mental Hygiene, Inc.

2 Etamon chloride supplied by Parke, Davis \& Company through the courtesy of Dr. E. C. Vonder Heide. the malignant phase of the disease and 4 in the benign phase. The results are shown in Figures 1 to 3 .

No tendency to develop a resistance to the depressor action of the drug was noted in any of the patients during the period of testing. There was, however, considerable day to day variation in both the magnitude of the depressor response and of the blood pressure "floor" reached. The minimum variation of the depressor response ( $80 / 44$ to 45 /

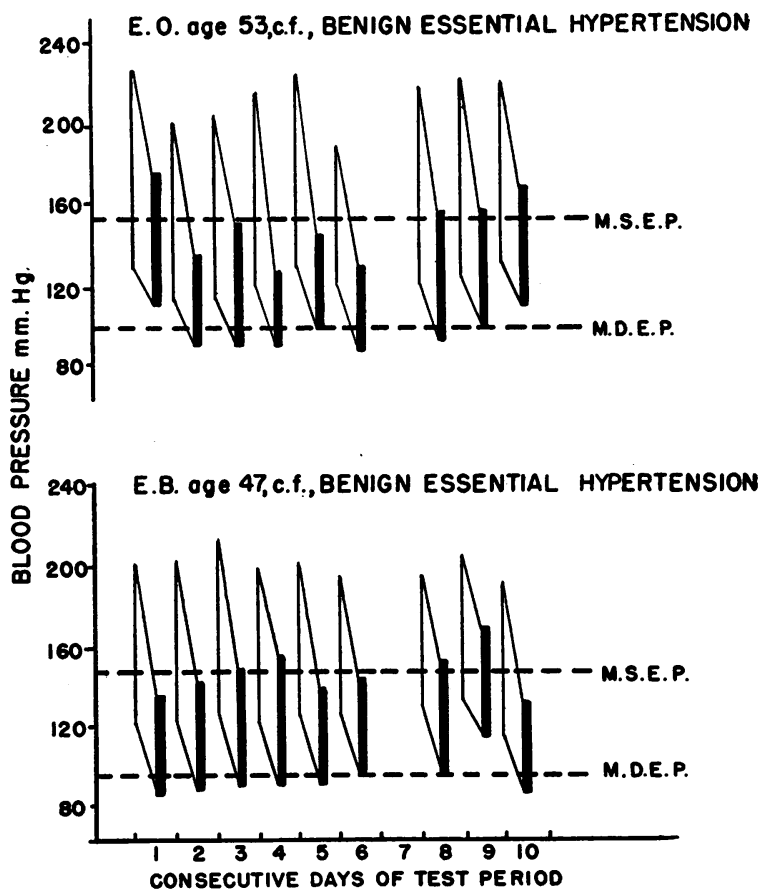

Fig. 1. Consecutive Depressor Responses to TEAC (Tetraethyl Ammonium Chloride)

Light vertical lines connect control systolic and diastolic blood pressures. Heavy vertical lines connect systolic and diastolic pressures at height of TEAC effect (TEAC floor). The 2 horizontal broken lines represent the mean systolic and diastolic endpoints (TEAC floor) of all determinations. Note the day to day variation in the TEAC floor and the lack of any evidence of increasing tolerance to the drug. 
$30 \mathrm{~mm} . \mathrm{Hg}$ ) occurred in patient E. H. (Figure 2), the maximum $(82 / 71$ to $18 / 1 \mathrm{~mm}$. $\mathrm{Hg})$ in patient

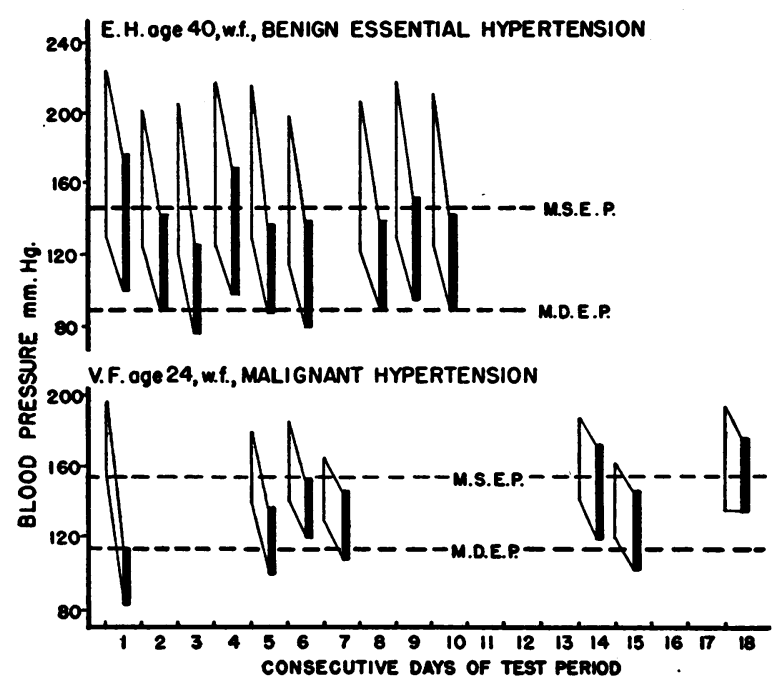

FIG. 2. See legend, Figure 1

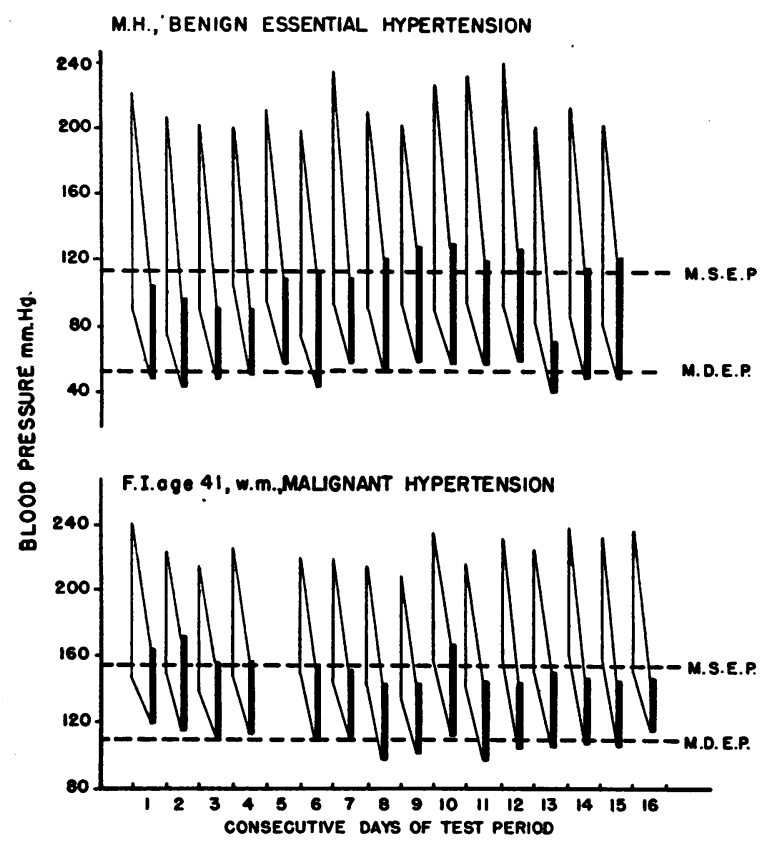

Fic. 3. See legend, Figure 1
V. F. (Figure 2). The fluctuations in the blood pressure floor varied from $170 / 114$ to $144 / 96 \mathrm{~mm}$. $\mathrm{Hg}$ in patient F. I. (Figure 3 ) to $176 / 135$ to 114 / $84 \mathrm{~mm}$. $\mathrm{Hg}$ in patient V. F. (Figure 2). No correlation could be demonstrated between variations in the initial height of blood pressure and the floor levels reached after tetraethyl ammonium chloride.

\section{SUMMARY}

Serial intravenous injections of tetraethyl ammonium chloride in 6 hypertensive patients revealed in all cases considerable daily fluctuation in both the magnitude of depressor response and the blood pressure floor. There was no evidence of the development of increasing tolerance to the depressor effect of the drug on repeated administration. For this reason, the data suggest that fluctuating humoral and neurogenic mechanisms interact as factors in clinical hypertension.

\section{BIBLIOGRAPHY}

1. Acheson, G. H., and Pereira, S., The blocking effect of tetraethyl ammonium ion on the superior cervical ganglion of the cat. J. Pharmacol. \& Exper. Therap., 1946, 87, 273.

2. Lyons, R. H., Moe, G. K., Campbell, K. N., Hoobler, S. W., Neligh, R. B., Berry, R. L., and Rennich, B., The effects of blockade of the autonomic ganglia in man. Preliminary observations on the use of tetraethyl ammonium bromide. Univ. Hosp. Bull., Ann Arbor, 1946, 12, 33.

3. Lyons, R. H., Moe, G. K., Neligh, R. B., Hoobler, S. W., Campbell, K. N., Berry, R. L., and Rennich, B. R., The effects of blockade of the autonomic ganglia in man with tetraethyl ammonium. Preliminary observations on its clinical application. Amer. J. M. Sc., 1947, 213, 315.

4. Acheson, G. H., and Moe, G. K., Some effects of tetraethyl ammonium on the mammalian heart. J. Pharmacol. \& Exper. Therap., 1945, 84, 189.

5. Acheson, G. H., and Moe, G. K., The action of tetraethyl ammonium ion on the mammalian circulation. J. Pharmacol. \& Exper. Therap., 1946, 87, 220. 